\title{
Compliance of Legal Regulation of the Republic of Lithuania with the EU Resolution on COVID-19 Vaccines
}

\author{
Ph.D. candidate Erika Statkiené \\ Institute of Public Law of Mykolas Romeris University \\ Klaipeda municipality, Lithuania \\ erstatkiene@stud.mruni.eu \\ Assoc. Professor Renata Šliažiené \\ Lithuania Business University of applied sciences \\ Klaipeda municipality, Lithuania \\ renata.sliaziene@ltvk.lt
}

\section{Abstract}

The aim of this article is to evaluate compliance of the legal regulation of the Republic of Lithuania with the EU resolution on Covid-19 vaccines. The main goal is to investigate the government implemented extraordinary legal measures to control the pandemic situation in Lithuania by processing the goal of planned COVID-19 vaccination quantities and to evaluate their compliance with the EU resolution on COVID-19 vaccine. By using qualitative analysis of scientific literature and documents, statistical data analysis, comparative method of legal acts analysis, the purpose to identify the possible consequences of inadequate legal regulation implementation, affecting observance of human rights and fundamental freedoms, have been exceeded. The article aims to indicate whether there are any unreasonable, over excessive, legal measures in Lithuanian government decisions in trying to control the epidemic and distribution of vaccinations, by implementing legal restrictions against non-vaccinated people. Also, whether legal measures are objectively discriminatory and what the risks of such implementation are. The goal of the research is to indicate the main imposing restrictions, such as non-provision of services, accessing them and getting free health services, not limiting employees to continue their work without the vaccination certificate, not allowing customers in supermarkets or restaurants etc., which causes certain differences between social groups, allowing a reasonable doubt for discriminatory manifestations to be raised, therefore indicating the violation of human rights and fundamental freedoms in the process.

Keywords: Lithuania, COVID-19, vaccination, restrictions on human rights. 
Erika Statkienè, Renata Šliažiené. Compliance of Legal Regulation of the Republic of Lithuania with the EU Resolution on COVID-19 Vaccines

\section{Introduction}

On March 15, 2020, the beginning of a quarantine was announced for the first time in Lithuania due to the outbreak of COVID-19 infectious disease. Therefore, Lithuanian government adopted hasty decisions and ensured the duration of the quarantine regime and the restrictions imposed by by-laws. Attempts to control the pandemic caused various discussions both for violation of Lithuanian citizens human rights and freedoms and for not complying with the unified legal acts adopted by the European Union during the pandemic in order to control it.

It should be noted that the first signs of possible human rights violations were observed among the disabled and other particularly sensitive social groups. Institutions for the disabled, such as care homes, nursing homes, etc. were closed to control the pandemic; relatives and other persons could not enter these institutions or visit their relatives; thus, such restriction did not help to control the pandemic in these institutions either.

By analysing various cases and the ongoing vaccination of the Lithuanian population, it is important to maintain a balance between restrictive legal measures and protection of human rights and freedoms. Human rights violations were also raised in the civil service when civil servants approached various law enforcement unions to report possible violations due to their forced vaccination. Article 14 of the Convention for the Protection of Human Rights and Fundamental Freedoms provides that the exercise of the rights and freedoms recognised therein shall be without discrimination on grounds of sex, race, colour, language, religion, political or other opinion, national or social origin, membership of a national minority or property, birth or other grounds (European Convention on Human Rights, 2010, No. 96-3016). Discrimination occurs when a person is treated differently in the media or in the state without any objective reason, when this has not previously caused any legal problems in assessing or the person is vaccinated or not.

The article analyses the situation with human rights in Lithuania to determine whether the government introduced compulsory vaccinations comply with a common EU approach to vaccine security and vaccination campaigns. Deviations from obligations under the European Convention on Human Rights in the context of the COVID-19 pandemic were analysed not only by lawyers, doctors, politicians and scientists, but also by people affected by the pandemic.

\section{Implementation of Proper Legal Regulation on COVID-19 Vaccines in Lithuania and Abroad}

Analysis of political and legal decisions of other countries in the implementation of the set vaccination goals have shown problems related to proper implementation according to the EU observance of ethical principles which guarantees human rights and fundamental freedoms. According to Indrani G. and Rama B., "both science and public policies 
around vaccines are fraught with uncertainties and ethical concerns. The COVID-19 pandemic itself has been marked by uncertainties across multiple domains - nature of the virus, alternative treatment options, clinical outcomes and prevention methods" (Indrani \& Rama, 2020).

Though, there are still no acceptable and adequate scientific and legal implementations to be constituted in most countries. Therefore, under the circumstances and the need for vaccines to stop the spread of pandemic, almost all countries started their vaccination process without researching further implications of the vaccine due to the seriousness of the extreme situation. The scientific community as well as entire population have raised reasonable concerns for safety of vaccines, availability, and equality problems, as well as accountability of distribution costs.

The vaccination process and implementation of legal regulation in this matter raises a lot of uncertainties in Lithuania - questions of financing the vaccines, effectiveness of those, considering that new virus strains have been detected and remaining active despite vaccination, as well as probable side effects of the vaccines, and the legality of implementation of legal restrictions for non-vaccinated people to maintain and obtain their human rights.

Therefore, there are various discussions considering implementation of massive vaccination taking into account emergency measures which have an impact on fundamental human rights (European Union Agency for Fundamental Rights, 2021). It has affected all human rights and allowed governments to impose restrictions. Thus, the question still remains who will ensure that granting Lithuanian government extraordinary decision-making power will not go beyond the necessary measures to protect human well-being, and there will be no excessive restriction in the field of freedom of movement, the right to access goods and services or the right to work and conduct business.

\section{Legal and Ethical Aspects of COVID-19 Vaccination in Context of Lithuanian Legislation}

On January 19, 2021, the European Commission adopted a communication, calling on Member States to step up the use of vaccines across the EU. The goal indicated that until 2021 at least $80 \%$ of vaccines should be use for vaccination in every Member State by the end of March. This would concern people over the age of 80 and at least $80 \%$ of health and social care professionals (Communication from the Commission Temporary Framework for State aid measures to support the economy in the current COVID-19 outbreak, 2020). Until 2021, Member States should have vaccinated at least $70 \%$ of the adult population by summer. Therefore, during the five months of vaccination, 988.5 thousand people were vaccinated against coronavirus with one or two doses of the vaccine, which constitutes $35 \%$ of the Lithuanian population. According to the data of the first week of August, $46.55 \%$ were vaccinated in Lithuania, of the entire population of Lithuania (Lithuanian department of statistics, 2021). 
As it can be seen from the mentioned figures, Lithuania is not reaching the set limit by the European Union. Four manufacturers of vaccines against COVID-19 were approved in Lithuania and still are in use: Vaxzevria (formerly AstraZeneca), Pfizer-BioNTech, Moderna, Johnson \& Johnson (On Approval of the Description of the Procedure for Organising Vaccination of the Population with COVID-19 Disease (Coronavirus Infection) Vaccine with State Budget Funds, 2021). This procedure provides full course of vaccination, facilities to implement it, and priority groups of persons who have priority for vaccination. It should be noted that throughout the pandemic period, Lithuanian legal framework did not adopt a single special COVID law which was implemented in other countries. Lithuania has limited itself to introducing many by-laws and updating the Law on the Prevention and Control of Communicable Diseases of the Republic of Lithuania (Republic of Lithuania Law On Prevention and Control of Communicable Diseases of Humans, 2001, current wording as of March 26, 2021).

In order to scrutinise the limitations of the situation of COVID-19 in Lithuania, it is necessary to review several amendments introduced by the Government of the Republic of Lithuania regarding the declaration of an emergency situation. The approved Resolution No. 152 "On the Amendment of the State Emergency Declaration" indicated which contact services, commercial and non-commercial cultural, entertainment, sporting events, celebrations, fairs, festivals or other temporary gatherings of people in a public place for a certain period of time meet the criteria set by the Government. The criteria stated that individuals must have received one of the mentioned vaccines for coronavirus infection; they may have had a history of disease of coronavirus infection; may have received a positive (less than 60 days ago) anti-S, anti-S1 or anti-RBD IgG antibodies to SARS-CoV-2) quantitative or semi-quantitative serological immunological test, unless the serological test is performed after vaccination; a person who has tested negative for a COVID-19 test has been subjected to a SARS-CoV-2 PCR test not earlier than 48 hours (from the time of sampling). Therefore, the Emergency State Operations Manual of the Ministry of Health of the Republic of Lithuania set out new requirements which have to be implemented since September 13, 2021, restricting the control of non-compliant individuals (i.e., unvaccinated or lacking any of the test results listed above).

Institutions are obliged to constantly control and supervise, report on compliance with restrictions when all contact services and economic activities are carried out and events are organised (except for established exceptions) only for persons who meet the criteria of the Opportunity Passport (The Emergency State Operations Manual of the Ministry of Health of the Republic of Lithuania, 2020). This new regulation stipulates that people who do not have a passport or do not meet the criteria will not be able to visit and shop in stores with an area of less than 1,500 square meters, in stores with separate entrance. Also, such non-immune people will not be able to visit beauty salons, catering establishments, entertainment venues, events, except for outdoor events with a maximum of 500 participants. There is also a new restriction that in addition to the passport in Lithuania, visits to veterinary services, museum expositions and exhibitions are shortened, 
libraries can be visited only for the purpose of collecting and returning books, contact must last no longer than 15 minutes.

These discriminatory aspects are not in line with the principles of international law in the assessment of the EU's recommendations stated in the EU resolution on COVID-19 vaccines. It should be noted that one aspect of the discriminatory legal framework concerns the reimbursement of COVID-19. This raises a number of questions, for example, the legal regulation considering foreigners who will be able to receive treatment from the state treasury, while Lithuanian citizens who do not meet the above requirements will not be reimbursed for treatment with COVID-19. Therefore, in the 2021 report of the Director of the State Health Insurance Fund under the Ministry of Health on August 17 order No. 1K-241, which replaces the June 30, 2005 order No. 1K-81 "On Isolation of Personal Health Care Services and Services Provided in Health Programs Paid from the Budget of the Compulsory Health Insurance Fund", in which one of the classifications is on services paid from state funds to foreigners illegally crossing the state border of the Republic of Lithuania due to COVID-19 sickness service (Director of the State Health Insurance Fund under the Ministry of Health on Isolation of Personal Health Care Services and Services Provided in Health Programs Paid from the Budget of the Compulsory Health Insurance Fund, 2017).

However, the next decision conducted on June 29, 2021 order No. V-1493 "On the Procedure for Organising a COVID-19 Disease (Coronavirus Infection) Vaccine Acquired from the State Budget for Vaccination of the Population" provides a target group to which compulsory health insurance must be provided from the state budget - only such citizens of the Member States and their family members who have come to reside in the Republic of Lithuania for more than 3 months in the six-months period and have acquired the right of residence in the Republic of Lithuania, foreign citizens and stateless persons who have been issued a document granting the right of residence in the Republic of Lithuania, upon arrival to live in the Republic of Lithuania, persons who have been issued a national visa, persons accredited and residing in Lithuania and other persons. It should be noted that based on the submitted by-laws, manifestations of discrimination can be seen because the introduction of the opportunity passport requirement, which is obtained only after vaccination or re-vaccination with COVID-19, will prevent noncompliant people from receiving relevant services.

It must be stated that the resolution of the European Union always emphasises that the duty of the state to ensure the freedom of choice of a person; however, after the introduction of certain by-laws, such freedom of choice may be discriminated against in Lithuania. The resolution of the European Union also emphasises that the state must clearly inform citizens of its country that they can choose to be vaccinated or not, while doubts remain as to whether these requirements are ensured and implemented in Lithuania. Lithuanian government is trying to control the epidemic and increase vaccination rate by implementing some legal restriction against non-vaccinated is not a discriminatory but a legal regulation that will impose restrictions such as non-provision 
of services, access to shops and getting free health services, causes certain differences between social groups, allows a reasonable opinion to be formed about discriminatory manifestations indicating violation of human rights.

In order to scrutinise the limitations of the situation of COVID-19 in Lithuania, it is necessary to review several amendments introduced by the Government of the Republic of Lithuania regarding the declaration of an emergency situation, mention should be made of Resolution No. 152 "On the Amendment of the State Emergency Declaration", which provides for contact services, commercial and non-commercial cultural, entertainment, sporting events, celebrations, fairs, festivals or other temporary gatherings of people in a public place for a certain period of time to meet the criteria set by the Government. The criteria state that individuals must have received one of the stated vaccines for COVID-19 (coronavirus infection); they may have had a history of COVID-19 disease (coronavirus infection); have received a positive (less than 60 days ago) anti-S, anti-S1 or anti-RBD IgG antibodies to SARS-CoV-2) quantitative or semi-quantitative serological immunological test, unless the serological test is performed after vaccination COVID-19 disease (coronavirus infection) vaccine; a person who has tested negative for a COVID-19 test has been subjected to a SARS-CoV-2 PCR test not earlier than 48 hours (from the time of sampling).

The State-level Emergency State Operations Manual of the Ministry of Health of the Republic of Lithuania sets out new requirements that will apply from September 13, 2021 (Emergency State Operations Manual of the Ministry of Health of the Republic of Lithuania, 2020) restricting control of non-compliant individuals (i.e., unvaccinated or lacking test results listed above). Institutions are obliged to constantly control and supervise, report on compliance with restrictions when all contact services and economic activities are carried out and events are organised (except for established exceptions) only for persons who meet the criteria of the Opportunity Passport. This new regulation stipulates that people who do not have a passport or do not meet the criteria will not be able to visit and shop in stores with an area of less than 1,500 square meters, in stores with separate entrance. Also, such non-immune people will not be able to visit beauty salons, catering establishments, entertainment venues, events, except for outdoor events with a maximum of 500 participants. There is also a new restriction that in addition to the passport in Lithuania, visits to veterinary services, museum expositions and exhibitions are shortened, libraries can be visited only for the purpose of collecting and returning books, contact must be kept under 15 minutes. These discriminatory aspects are not in line with the principles of international law in the assessment of the EU's recommendations stated in the EU resolution on COVID-19 vaccines (Council of Europe "Covid-19 vaccines: ethical, legal and practical considerations" Resolution 2361, 2021).

It should be noted that one aspect of the discriminatory legal framework concerns reimbursement of COVID-19. This raises several questions, as the legal regulation on this issue stipulates those foreigners will be able to receive treatment from the state 
treasury, while Lithuanian citizens who do not meet the above requirements will not be reimbursed for treatment with Covid-19. This is noted in the August 17, 2021 report of the Director of the State Health Insurance Fund under the Ministry of Health, order No. 1K-241, which replaces the June 30, 2005 order No. 1K-81 "On Isolation of Personal Health Care Services and Services Provided in Health Programs Paid from the Budget of the Compulsory Health Insurance Fund", in which one of the classifications is on services paid from state funds to foreigners illegally crossing the state border of the Republic of Lithuania due to COVID-19 sickness service.

However, in the next June 29, 2021 order No. V-1493 "On the Procedure for Organising a COVID-19 Disease (Coronavirus Infection) Vaccine Acquired from the State Budget for Vaccination of the Population" provides a target group to which compulsory health insurance must be provided from the state budget - only such citizens of the Member States and their family who have come to reside in the Republic of Lithuania for more than 3 months within the period of six months and have acquired the right of residence in the Republic of Lithuania, foreign citizens and stateless persons who have been issued a document granting the right of residence in the Republic of Lithuania, upon arrival to live in the Republic of Lithuania, persons who have been issued a national visa, persons accredited and residing in Lithuania and other persons.

It should be noted that based on the submitted by-laws, manifestations of discrimination can be seen, because the introduction of the opportunity passport requirement, which is obtained only after vaccination or re-vaccination with COVID-19, will prevent non-compliant people from receiving relevant services, which can be considered discrimination, as well as the formation of appropriate negative attitudes towards them, both through media and in society.

It must be stated that the resolution of the European Union emphasises the duty of the state to ensure the freedom of choice of a person; however, after the introduction of certain by-laws, in Lithuania such freedom of choice may be discriminated against. The resolution of the European Union also emphasises that the state must clearly inform its citizens to freely choose to be vaccinated or not, while doubts remain as to whether these requirements are ensured and implemented in Lithuania. Lithuanian government is trying to control the epidemic and increase the vaccination rate by implementing some legal restrictions against the non-vaccinated, which is not considered discriminatory but a legal regulation that will impose restrictions such as non-provision of services, access to shops and getting free health services, causing certain differences between social groups, allowing a reasonable opinion to be formed about discriminatory manifestations indicating violation of human rights.

Rateesh Sareen notes that "adverse reaction to vaccines have been reported from various countries with scepticism about their efficacy and safety as the vaccines has been developed in short time with limited availability of data on safety and efficacy" (Sareen, 2021). The same worries occurred in Lithuania as well. There is reasonable doubt for the not cleared vaccines and the not completed process of clinical trials. It should take a lot of years 
to develop a vaccine for other diseases; therefore, in currently COVIDd-19 vaccines are likely created by demand and supply proportions raising the question of safety and benefit to all humanity if the outcomes in several years after vaccination will arise.

The question is raised of who will take responsibility in this case and who will be responsible for spending unreasonable sums of money for a vaccine which has untreatable side effects or will not be effective after other virus strains attack. Sareen indicates that

\begin{abstract}
"justice refers to ethical obligation to treat each person in accordance with what is morally right and proper and to give each person what is due to him or her. We are well aware that in clinical trials patients are subjected to untested new treatment and are expressed to unknown risks. The guidelines make it mandatory to obtain free and informed consent by participants. Free consent is the one that is not being procured by fraud, misrepresentation or coercion" (Sareen, 2021).
\end{abstract}

Therefore, who will ensure that informed consent will be provided properly to each and every person, informing the participant of negative reaction, effects of vaccine and probable risks. Sareen raises a reasonable question which is relevant in Lithuania as well whether the self-interest of political governance of the country for effective COVID-19 control could make them persuasive.

It should be noted that the analysis of the European Union resolution indicates that the state must disseminate clear information on safety of vaccines and possible side effects on human health. According to Debbie Porteous

\footnotetext{
"If the patient is on anticoagulants, they need to be advised of the risk of haematoma and the vaccinator should take care to apply pressure after vaccination. Previous allergic reactions including anaphylaxis may result in a different vaccine being selected or the administration being delayed. Before giving a COVID-19 vaccine, vaccinators must ensure that they have obtained informed consent from the patient or that a best interest decision has been made if the patient does not have mental capacity at the time of vaccination. To be able to consent to vaccination, the vaccinee should receive an explanation of the treatment and its benefits and risks, ideally verbally from a clinician." (Porteus, 2021)
}

Thus, the European Commission states that the Commission will promote the COVID-19 vaccine as a global public good. The question arises as to whether the current vaccine is already a common good. Currently, there are no long-term research indicating side effects, fertility or birth rates in healthy children; in case side effects appear, it is questionable whether the vaccine will still be considered a common good and who will then take responsibility - the European Commission, pharmaceutical companies or the countries themselves that already have implemented the vaccination process to ensure the common good. Under the signed agreements, Member States are required to procure specific doses of vaccines according to a set schedule, assuring Pfizer, for example, that it will irrevocably and unconditionally comply with the terms of this Agreement, including liability for damages, which again raises the question whether this can be considered an appropriate way to achieve the common good.

According to the Action brought on 19 May, 2021 against the European Commission, the applicants, Heidi Amort (Jenesien, Italy) and 22 other applicants, represented by 
R. Holzeisen, a lawyer, brought actions for annulment of the contested implementing decision, its amendments and additions, in relation to the action of 11 March, 2021. The European Commission Implementing Decision C (2021) 1763 grants a conditional marketing authorisation pursuant to Regulation (EC) No. 726/2004 of the European Parliament and of the Council for the medicinal product for human use "COVID-19 Vaccine Janssen - COVID-19 Vaccine (Ad26.COV2-S [recombinant])" (Case T-267/21, 2021). The action is based on the ground that the contested implementing decision infringes Article 2 (1) and (2) of Regulation (EC) No. 507/20061. According to the applicants, it has been scientifically proven that the worldwide scaremongering about the allegedly high mortality rate associated with SARS-CoV-2 infection is unfounded. Moreover, the WTO and the EU have incorrectly identified the critical situation as a public health risk.

Second plea in law alleging that the contested implementing decision infringes Article 4 of Regulation (EC) No. 507/2006 in that the balance between the risks and benefits of the medicinal product as referred to in Article 1 (28a) of Directive 2001/83/ EC2 has not been established; and the condition in Article 4 (1) (b) of Regulation (EC) No. 507/2006 is not satisfied, as it appears that the applicant will not be able to provide complete clinical data. The application states that the condition in Article 4 (1) (c) of Regulation (EC) No. 507/2006 is not fulfilled, as the needs of persons for whom there are no suitable medicines will not be met, and that the condition in Article 4 (1) (d) of Regulation (EC) No. 507/2006 is not fulfilled.

The other plea in law alleges infringement of Regulation (EC) No. 1394/20073, Directive 2001/83/EC and Regulation (EC) No. 726/20044, as well as a grave breach of Articles 168 and 169 TFEU and Articles 3, 35 and 38 of the EU Charter. As the decision is pending, but it can be expected that many more similar statements on the above grounds may be made, the validity of the decisions and their compliance with fundamental principles and international law should be considered before making relevant decisions in relation to the Covid pandemic.

According to the New York Times,

"Pfizer-BioNTech and Moderna both increased the price of their coronavirus vaccines in their latest contracts with the European Union. [...] Clément Beaune, did not specify the exact rises in price. But as the more contagious Delta variant continues to spread across the continent, he said that the increases were justified [...]. His comments followed an article in the Financial Times on Sunday that said the price for a Pfizer-BioNTech shot had risen to $\$ 23$ from about $\$ 18.50$ in the contracts, and that Moderna's had risen to \$25.50, up from \$22.60." (Pronczuk \& Gallois, 2021)

All these solutions would be appropriate if we assume that the COVID-19 pandemic will continue for at least another three years, during which time people should be vaccinated with the vaccine at least eight times, even though a third dose is not currently registered in Pfizer indications. Considering that the vaccines currently in use only have a conditional registration granted by the European Medicines Agency under exceptional, pandemic conditions, implemented under a special legal regime in force in country, it can 
be stated that, depending on the situation and the measures adopted, until the vaccine is developed and registered, Lithuania and other EU Member States which have signed agreements with pharmaceutical companies, will have to maintain special legal regime, to proceed with the use of the vaccines.

Therefore, there is a direct link between the obligation to use these vaccines and the need for quarantine or other special legal regimes in the Member States that restrict human rights and other constitutional values. Such redemption of vaccine doses in the future is potentially contrary to implementation of the principles of international law and could turn the European Union and its Member States into hostages of pharmaceutical companies for at least a few years with no possibilities to withdraw from the signed contracts or liability for possible harm to human health from developed vaccines. The extent of the restriction of human rights and freedoms must be objectively assessed and weighed against the relevant limits of the constitutional principle of proportionality in the rule of law, in accordance with applicable law, assessing the possible consequences. As long as there are no science-based, adequate measures without isolation, vaccinations or masks to protect society from the spread of the pandemic, all these restrictions are justified, but if vaccinated and non-vaccinated people are restricted to access free medical care when contributions to the compulsory social insurance fund are paid, it is not considered an appropriate legal regulation because it violates a person's constitutional rights and restricts freedoms inappropriately. In the analysed case, it is necessary to properly identify what a legal public greater good really is and weigh the chosen means to achieve and ensure it.

Opinions often differ on the purchase and use of pharmaceuticals and vaccines and their positive impact on pandemic management. In one case, multinational pharmaceutical companies, supplying vaccines to the Member States of the European Union, have legitimate safeguarding of the common good. As the virus has already identified strains in which the vaccines ordered do not work or at least do not work as effectively, there is reasonable doubt that ordering large quantities of vaccines and justifying such costs in the general interest is unclear or will be guaranteed.

According to the results of investigation of Abas Khan and Mohd Sarwar Mir, the main problem of refusal to vaccinate were addressed to "concerned about the side effects $(40 \%)$, safety and lack of information regarding the vaccine $(20 \%)$. Some were not willing to accept vaccination due to religious $(8.8 \%)$ and cultural $(4.8 \%)$ reasons, belief in traditional remedies (3\%) and fear of injection (16.1\%)" (Khan \& Sarwar, 2021). All the stated reasons, unlike in Lithuania, were subjective, not based on political decisions, threatening to deprive unvaccinated persons of certain rights, or additional costs related to medical expenses, testing and other measures restricting pressure affecting and influencing the freedom of choice.

Analysing the situation in Africa, the reasons for resistance to be vaccinated were the concerns that the vaccines were too new and there were worries about possible side effects; concerns have been extensively documented in studies on COVID-19 vaccine 
acceptance in other settings and the vaccine hesitancy literature more broadly (Khan, Sarwar, 2021). These apprehensions may, however, be heightened for COVID-19 vaccines due to the unprecedented speed at which they were developed and approved as well as their novelty. The latter has indeed been the case for other new vaccines, to cure other diseases.

Thus, the research of Sara Cooper, Heidi van Rooyen and Charles Shey Wiysonge have identified several main problems for the implementation of the foreseen goals of vaccination. Political decision making was the most influenced factor for "not trusting the government's capability in ensuring that the vaccine is safe and effective, and believing that politics played too much of a role in the vaccine development process, accounted for $14 \%$ and $8 \%$ of the total reasons for not wanting to get COVID-19 vaccination respectively" (Cooper et al., 2021). It should be noted that there is no denying that measures are worthwhile, but legal implementation of vaccination process must respect the EU rules indicating that everyone is free to choose whether or not to be vaccinated not only because of their state of health, but also since this choice should not discriminate against anyone in the same way as freedom of choice neither in political, economic nor legal matter with no pressure applied.

Nevertheless, provisions of the resolution are not compliable in the Lithuanian legislation, which imposes mandatory reimbursement of medical expenses for COVID and non-vaccinated persons to be treated, or a compulsory 7-day check of SARS-CoV-2 test at one's own expense to get accepted to work, or failure to provide appropriate services without providing proof of completed vaccination even if there is a case of naturally obtained immunity or personal reasons not to vaccinate. It should be noted that utilitarianism alone cannot be relied upon to restrict human rights, which must be based on the constitutional principle of proportionality, encompassing all components of the content and restriction of human rights. Thus, when testing people who cannot be vaccinated due to their health condition or other objective reasons, even simply because they do not want to be vaccinated (which the EU resolution must ensure without discrimination without pressure), their tests must be paid for by all taxpayers. In this case, ensuring appropriate free treatment in medical institutions.

It should be noted that Robert Böhm's research results indicated that the introduction of partially compulsory vaccination and its externality effects on voluntary vaccination have significant importance (Böhm, 2016). Thus, factors that reduce freedom of choice may decrease motivation and lead to a counterproductive psychological response to voluntary vaccination. The study showed that forced vaccination increased people's anger levels, i.e., negative attitudes towards vaccination, whereas voluntary vaccination did not. These results should be considered before combining legal legislation mechanism, which is based on restriction, penalties and creating an emotional fare of society. This resulted a $39 \%$ reduction in vaccination demand during the second voluntary vaccination (reactivity). Taking into consideration that this negative effect was particularly pronounced in those who were reluctant to vaccinate from the beginning, there could 
be a threat for public hesitation increase due to harms of compulsory vaccination. Thus, introduction of compulsory vaccination may have a detrimental effect when compared to voluntary vaccination.

Analysis of the results of Martins and Teixeira article also indicated that the factors which reduce freedom of choice can affect motivation and lead to a counter-psychological reaction to voluntary vaccination (Martins \& Teixeira, 2020). In the study, the authors identified that forced vaccination increased people's anger levels, as well as negative attitudes towards vaccination, whereas voluntary vaccination did not. The data from the experiment showed that this has a particular effect (increased anger) on people who were reluctant or hesitant to vaccinate. Thus, introduction of compulsory vaccination may have a detrimental effect when contrasted to voluntary vaccination.

It should be mentioned that before changing the legal legislation or creating it to the benefit of greater good for vaccination implementation, the historical data analysis is required as well. Historical research data suggests historical fact analysis comparing Brazil as a country in 1904 when it implemented compulsory vaccination against smallpox (Giubilini \& Alberto, 2020). Only those who had been vaccinated were allowed to enter employment contracts, obtain travel documents, study, enrol in universities, etc. This compulsory vaccination showed that, even with the rising number of smallpox cases in Rio de Janeiro, some of the population still rejected the vaccination, spreading rumours and causing a backlash, because forced vaccination provokes anger among the population rather than encouraging them to get vaccinated in the first place. In this case, historical facts show that the smallpox epidemic was not contained by forced vaccination, but rather by a counterproductive approach that the Brazilian government had to abandon. It was only later, as the epidemic intensified that people voluntarily vaccinated themselves. Therefore, Lithuania could follow the experience of such counties and take into consideration the ways of managing the pandemic situation without legally forcing, using restriction to nonvaccinated people, not to get some services or other benefits.

The above-mentioned research indicates the analogy and parallel of situation with vaccination and taxation policy. According to the author's opinion, refusal to vaccinate could be compared with tax evasion. It is argued that compulsory vaccination is withholding of valuable social goods or services from families who choose not to vaccinate their children for non-medical reasons. However, there are also reasons that justify a legal rather than merely moral obligation to pay taxes; when public and collective goods have an important function in maintenance of society, it is legitimate to require individuals in the community to fulfil their moral obligations. Paying taxes to finance these goods is not only an immoral obligation but it should also be, as indeed it usually is, a legal obligation. With the exception of certain liberal circles, the idea that it is legitimate to legally require people to pay taxes, at least those needed to fund "supposedly useful" fairly widespread goods and are regarded as indisputable. Harm to others and benefit to others are moral reasons for adopting certain behaviours; thus, in current case, they justify a collective moral responsibility to grasp herd immunity. The moral duty to vaccinate should become 
a legal obligation, still argued that compulsory vaccination cannot be made on the basis of harm to others alone. Instead, compulsory vaccination is reinforced by considerations of justice. Therefore, it could be noted that refusing a vaccine is morally tantamount to tax evasion and could be legally treated as tax evasion. The author believes that it should be illegal not to vaccinate unless there are medical reasons for not doing so.

Thus, the comparison and analogy have its adequate insights. The previous research indicating non effectiveness of compulsory vaccination should be considered; taxation system and health, life, and interests of society, as well as expenses of buying vaccines have differences in the sphere and severity of the situation; therefore, could be applied as analogy creating reasonable doubt of the efficacy of compulsory tax burden.

Analysis of ethical and legal issues related to the implementation of vaccination in other countries have shown that it is not only Lithuania having difficulties in ensuring proper implementation of legal regulations that would not violate human rights and freedom to make decisions related to health. There are other problems and risks to be examined before proceeding with the global vaccination, as stated in the article "Pregnant women are at higher risk of severe COVID-19 disease with an associated risk of pre-term birth. Clinical trial data is insufficient currently to assess safety and efficacy of COVID-19 vaccinations in pregnant women, or indeed to recommend routine use in pregnancy". Thus, vaccination could be equally presumed to be unsafe for solid individuals as well, similarly to the research based on safety of vaccination for expectant women since current researches are is still ongoing. Before implementing legal instruments for ensuring high rate of vaccination in the country, it should be considered whether it will have an influence on a person's individual decision making with no pressure or risk to be discriminated for their decision, restricted to use of their rights, or being influenced by economical encumbrance which could be conditioned due to their self-determination.

At the EU level, civil liability of a producer of immunological medicinal products is defined by the Directive the approximation of the laws, regulations and administrative provisions of the Member States concerning liability for defective products (hereinafter in the text: Directive 85/374), which establishes a specific system of producer liability for defective products. One of the prerequisites for producer liability is a product defect, which is determined by evaluation of the consumer expectations of the product based on the safety approach (Article 6 of Directive 85/374). The effect of a drug is inseparable from physiological properties of the consumer, and side effects are the result of interaction of the drug with the chemical processes in the human body. Therefore, the same drug can have different effects on individual consumers with a variety of possible side effects and levels of harm associated with those risks.

It is also important to keep in mind that a medicinal product itself, as a particular product, is always characterised by complexity and intricacy, which distinguishes it from any conventional products used by the consumer. A consumer without expert knowledge will objectively not have an opportunity to determine whether a particular medicinal product could be considered defective and therefore would not be able to make 
a reasonable assessment of the safety they are entitled to expect in relation to a particular medicinal product. In these circumstances, it is assumed that the basis of consumer expectations for medicinal products (including vaccines) should be different from that for other products (Kisielytė-Reches, 2021).

\section{Conclusions}

For Lithuania to properly implement the vaccination process, ensuring proper implementation of human rights and freedoms, it is necessary to use the Constitution and the fundamental constitutional values such as the rule of law, democracy and protection of human rights and fundamental freedoms. It should be noted, that decisions on the purchase of vaccines must comply with the principles of openness and transparency, organising consultations with the population, medical personnel, legal representatives and scientists rather than operating and implementing a one-sided decision made by the government authorities. The treatment method and all precautions chosen must be influenced by coercive political methods, but on the basis of a reasonable scientific factual finding through the medium which practises and works according to the principle of neutrality. The implemented measures should ensure compliance with the norms established by the Constitution of the Republic of Lithuania, European Human Rights and Fundamental Freedoms convention, EU resolution on COVID-19, which oblige to protect the rights, fundamental freedoms, non-discrimination of their choice, ensuring proper information before obtaining the consent of a duly informed person. As long as there are no adequate measures without isolation, vaccinations or masks to protect society from the spread of the pandemic, all these restrictions are justified. However, in the case of vaccinated and non-vaccinated people segregation, by using restriction to use their rights to free medical care, receiving services, ensuring employment, the legal regulation considered must be compliant with the EU legal regulations, and cannot be justified for the violation of a person's constitutional rights and restriction of freedoms.

Historical research data indicates that the implemented compulsory vaccination against smallpox by using restrictions such as entering employment contracts, obtaining travel documents, studying, enrolling in universities, does not help to contain the pandemic situation. Forced vaccination could have a counterproductive approach for seeking the goal to manage the pandemic. The factors which reduce freedom of choice may decrease the motivation and lead to a counterproductive psychological response to voluntary vaccination. The study showed that forced vaccination increases people's anger levels, forms negative attitudes towards vaccination; voluntary vaccination, however, does not. Thus, the results should be considered before implementing legal restriction into legislation of Lithuania, based on restriction, penalties and creating an emotional fare of society. A negative effect could be particularly pronounced in those who are reluctant to vaccinate, there could be a threat for public hesitation increase, due to harms 
of compulsory vaccination, leading to the danger that implementation of compulsory vaccination may have a detrimental effect.

The Action brought against European Commission for annulment of the contested implementing decision, its amendments, and additions relating to them being scientifically proven that the worldwide scaremongering about the allegedly high mortality rate associated with SARS-CoV-2 infection is unfounded. Moreover, the European Union has incorrectly identified the critical situation as a public health risk, alleging that the contested implementation of decision infringes the balance between the risks and benefits of the medicinal product, which has not been established according to the legislation of the European Union. The application states that the condition in Regulation is not fulfilled, as the needs of persons for whom there are no suitable medicines will not be met, and that infringement of Regulations and Directives breach the EU legislation provisions. Thus, decision is pending, but it can be expected that more statements on the above grounds could be presented in the future. Therefore, validity of national legal decisions and their compliance with fundamental principles and international law should be evaluated before implementation of such decisions.

Therefore, in one way, on acting on behalf of legitimate cause, to achieve the addressed vaccination goals by ensuring the control of epidemic using the implementation of approved legal restriction against non-vaccinated persons could be not considered as a sure case of discrimination. Legal regulation, which will impose restrictions such as non-provision of services, access to supermarkets, medical institution, work place, or getting free health services, causes certain differences between social groups, and allows for a reasonable argument considering discriminatory manifestations, indicating violation of human rights and freedoms to choose with no pressure involved, which mismatches the compliance with the EU resolution on COVID-19 vaccines.

\section{Bibliography}

1. Betsch, C., \& Böhm, R. (2016). Detrimental effects of introducing partial compulsory vaccination: experimental evidence. European Journal of Public Health, 26(3), 378-381. https://academic. oup.com/eurpub/article/26/3/378/2467110.

2. Communication from the Commission Temporary Framework for State aid measures to support the economy in the current COVID-19 outbreak (2020/C 91 I/01). https://eur-lex.europa.eu/ legal-content/EN/TXT/HTML/?uri=CELEX:52020XC0320(03)\&from=LT.

3. Cooper, S., Rooyen, H., \& Wiysonge, Ch. (2021). COVID-19 vaccine hesitancy in South Africa: how can we maximize uptake of COVID-19 vaccines?", UK Limited, trading as Taylor \& Francis, Expert Review of Vaccines. https://www.tandfonline.com/doi/full/10.1080/14760584.2021.1949291.

4. Council of Europe "Covid-19 vaccines: ethical, legal and practical considerations" Resolution 2361, 2021. https://pace.coe.int/en/files/29004/html.

5. Court of Justice of the European Union CAS 2021, Amort and Others v Commission, Case T-267/21. https://op.europa.eu/en/publication-detail/-/publication/c442f878-dd74-11eb-895a01aa75ed71a1. 
6. Director of the State Health Insurance Fund under the Ministry of Health on Isolation of Personal Health Care Services and Services Provided in Health Programs Paid from the Budget of the Compulsory Health Insurance Fund (2017). https:/e-seimas.lrs.lt/portal/legalAct/lt/TAD/ TAIS.289872/asr.

7. Dubé, E., Gagnon, D., MacDonald, N., Bocquier, A., Peretti-Watel, P., \& Verger, P. (2021). Underlying factors impacting vaccine hesitancy in high inco,me countries: a review of qualitative studies. Expert Rev Vaccines. https://pubmed.ncbi.nlm.nih.gov/30359151/.

8. European Union Agency for Fundamental Rights. (2021). The Fundamental Rights Report 2021. Luxembourg: Publications Office of the European Union. https://fra.europa.eu/en/publication/2021/fundamental-rights-report-2021.

9. European Commission Decision on approving the agreement with Member States on procuring Covid-19 vaccines on behalf of the Member States and related procedures, Brussels, (2020) 4192 final. https://ec.europa.eu/info/sites/default/files/annex_to_the_commission_decision_ on_approving_the_agreement_with_member_states_on_procuring_covid 19_vaccines_on_ behalf_of_the_member_states_and_related_procedures_.pdf.

10. Fournet, N., Mollema, L., Ruijs, W. L., ... \& van Steenbergen, J. E. (2018). Under-vaccinated groups in Europe and their beliefs, attitudes and reasons for non-vaccination; two systematic reviews. BMC Public Health, 18(1), 196. https://pubmed.ncbi.nlm.nih.gov/29378545/.

11. Giubilini, A. (2019). An Argument for Compulsory Vaccination: The Taxation Analogy. Journal of Applied Philosophy, 37(3), 446-466. https://onlinelibrary.wiley.com/doi/full/10.1111/japp.12400.

12. Gupta, I., \& Rama, B. (2020). Economics \& ethics of the COVID-19 vaccine: How prepared are we? Indian J Med Res, 152, 153-155. https://www.ncbi.nlm.nih.gov/pmc/articles/PMC7853278/.

13. Khan, A., \& Sarwar, M. (2021). Acceptance of COVID 19 Vaccine in India. Biomedical Journal of Scientific E Technical Research. https://biomedres.us/pdfs/BJSTR.MS.ID.006044.pdf.

14. Kisielytè-Reches, U. (2021). Consumer confident: the case of the Baltic states during Covid-19. The 9th International Scientific Conference for Young Researchers. Mykolas Romeris University STICS 2021, Vilnius, No. 3-4. https://repository.mruni.eu/bitstream/handle/007/17641/ CROMA_2021_9_2_15-24.pdf? sequence=1.

15. Lithuanian Department of Statistics. https:/experience.arcgis.com/experience/cab84dcfe0464c2a8050a78f817924ca.

16. Marshall, S., Fleming, A., Moore, A. C., \& Sahm, L. J. (2019). Views of parents regarding human papillomavirus vaccination: a systematic review and meta-ethnographic synthesis of qualitative literature. Res Soc Admin Pharm, 15(4), 331-337. https://pubmed.ncbi.nlm.nih.gov/29804879/.

17. Martins, C. M, \& Teixeira, J. C. (2020). Compulsory Vaccination: The Limit between Public and Private. Thieme Medical Publishers, 42(12/2020). https://pubmed.ncbi.nlm.nih.gov/33348393/.

18. Porteous, D. (2021). COVID-19 vaccines and vaccine administration. British Journal of Nursing (Mark Allen Publishing). https:/www.magonlinelibrary.com/doi/full/10.12968/ bjon.2021.30.6.344.

19. Pronczuk, M., \& Gallois, L. (2021). Pfizer and Moderna raised their vaccine prices in their latest E.U contracts. Journal The New York Times. https://www.nytimes.com/2021/08/02/world/pfizerand-moderna-raised-their-vaccine-prices-in-their-latest-eu-contracts.html.

20. Republic of Lithuania Law on the Prevention and Control of Communicable Diseases of Humans. 2010, current wording as of 26 March 2021. https:/e-seimas.lrs.lt/portal/legalAct/lt/ TAD/TAIS.373789?jfwid=nz8qn82xx\&fbclid=IwAR2GLw6SdtU_VgGFk4i2kJv8y-UxK_DPD_ GX1iHPeXoBd3yfRlVhY3AO3oA. 
Erika Statkienè, Renata Šliažiene. Compliance of Legal Regulation

of the Republic of Lithuania with the EU Resolution on COVID-19 Vaccines

21. Sareen, R. (2021). COVID-19 Vaccination and Ethics. Journal of Pulmonary Medicine, SciTechnol, International publisher of science, Technology and Medicine, Pathology Department, Memorial Hospital and Research Center, India. https://www.scitechnol.com/peer-review/covid19-vaccination-and-ethics-jECI.php?article_id=14377.

22. Smith, D., Attwell, K., \& Evers, U. (2021). Support for a COVID-19 vaccine man date in the face of safety concerns and political affiliations: an Australian study. Politics. https://journals.sagepub. com/doi/10.1177/02633957211009066.

23. The State-level Emergency State Operations Manual of the Ministry of Health of the Republic of Lithuania. 2020, No. V-2347. https:/vrm.Irv.lt/uploads/vrm/documents/files/LT_versija/ Sprendimas\%20Nr_\%2010V-64.pdf. 